Bailey, H.N., Bernier, A., Bouvette-Turcot, A.-A., Tarabulsy, G.M., Pederson, D.R., \& BeckerStoll, F. (2016). Deconstructing maternal sensitivity: Predictive relations to mother-child attachment in home and laboratory settings. Social Development. Advanced online publication, DOI 10.1111/sode. 12220 


\begin{abstract}
Despite the well-documented importance of parental sensitivity for child development, there is a lack of consensus regarding how best to assess it. We investigated the factor structure of maternal caregiving behavior as assessed at 12 months by the Maternal Behavior Q-Sort (Pederson, Moran, \& Bento, 1999) with 274 mother-infant dyads. Subsequently, we examined associations between these empirically-derived dimensions and child attachment, assessed in the home and laboratory (final $N=157$ ). Three dimensions of maternal behavior were identified, corresponding fairly closely to Ainsworth's original scales. They were labeled Cooperation/Attunement, Positivity, and Accessibility/Availability. Only Cooperation/Attunement consistently predicted home-based attachment at 15 months and 2 years, and at comparable strength to the overall sensitivity score, suggesting that this construct may be central to sensitivity. At 18 months, compared to their primarily secure counterparts, different types of laboratory-assessed insecure attachment were associated with different patterns of maternal behavior. Mothers in avoidant relationships $(\mathrm{n}=18)$ were low on Cooperation/Attunement and Accessibility/Availability, but fairly high on Positivity. Mothers of disorganized infants $(\mathrm{n}=11)$ were Cooperative/Attuned but somewhat less Positive toward, and less Accessible/Available to, their infants. A multi-dimensional approach to parental behavior may facilitate the identification of parenting precursors of insecure parent-child relationships.
\end{abstract}

Keywords: attachment, maternal sensitivity, multidimensional approach, factor analysis, assessment. 


\section{Deconstructing maternal sensitivity: Predictive relations to mother-child attachment in home and laboratory settings}

A long tradition of empirical research has provided compelling support for the classic assumption that early parent-infant relationships exert a determining influence on child development. As documented by meta-analytic reviews (e.g., Fearon, Bakermans-Kranenburg, Van IJzendoorn, Lapsley, \& Roisman, 2010; Groh, Roisman, Van IJzendoorn, BakermansKranenburg, \& Fearon, 2012), by longitudinal studies spanning up to 30 years of development (Fraley, Roisman, \& Haltigan, 2013; Raby, Roisman, Fraley, \& Simpson, 2015), and by experimental studies (Guttentag et al., 2014; Kochanska, Kim, Boldt, \& Nordling, 2013), parenting and early parent-child interactions constitute fundamental building blocks of child competence and adaptation throughout infancy, childhood, and adolescence.

Attachment theory was built upon the central assertion that caregiver sensitivity to infant cues is essential to the development of a secure attachment relationship (Ainsworth, Bell, \& Stayton, 1971; Ainsworth, Blehar, Waters, \& Wall, 1978). Over the years much evidence has accumulated to support this claim. Meta-analytic studies have confirmed a modest yet robust association between parental sensitivity and parent-child attachment security, whether assessed in the home or laboratory (Atkinson et al., 2000; De Wolff \& Van IJzendoorn, 1997; Goldsmith \& Alansky, 1987). Furthermore, sensitivity-focused interventions have demonstrated its influential role in the development of a secure attachment relationship (Bakermans-Kranenburg, Van IJzendoorn, \& Juffer, 2003).

Although prediction of individual differences in attachment security was the primary aim behind the development of sensitivity measures, parental sensitivity has proven useful in predicting many other aspects of infant and child adaptation, often in the socio-emotional sphere 
(e.g., Leerkes et al., 2009; NICHD Early Child Care Research Network [ECCRN], 1998), but also in biological and cognitive domains (Beckwith, Cohen, \& Hamilton, 1999; NICHD ECCRN, 2005; Smith, Landry, \& Swank, 2006). Longitudinal studies indicate that maternal sensitivity experienced during the first three years of life is associated with youths' social competence and academic skills through mid-adolescence and adulthood (Fraley et al., 2013; Raby et al., 2015). Taken together, this research demonstrates that the assessment of parental sensitivity is a powerful tool that captures a most salient aspect of infants' early experience.

In spite of the consensus regarding the importance of sensitivity as a construct, there is a notable lack of consensus regarding its assessment. A recent search found more than 50 distinct observation-based instruments used to assess sensitivity (Mesman \& Emmen, 2013). In an earlier review, De Wolff and Van IJzendoorn (1997; see also Nievar \& Becker, 2008) arranged sensitivity assessment instruments into conceptually distinct groupings based on behaviors considered central to parental sensitivity; some were judged by expert raters to more closely approximate Ainsworth's ideas about sensitivity than others. It is a matter of debate, therefore, whether the sensitivity construct is narrow, or encompasses a broad range of behaviors and characteristics, and which behaviors are central to its assessment.

Ainsworth et al. (1978) developed four maternal care scales. Three of the scales, Acceptance vs. Rejection, Accessibility vs. Ignoring, and Cooperation vs. Interference, describe behaviors that they considered centrally relevant to a comprehensive assessment of parental sensitivity (Ainsworth, Bell, \& Stayton, 1974). Although highly inter-correlated (Ainsworth et al., 1978), the scales were not viewed as redundant, since accurate assessment on the fourth Sensitivity vs. Insensitivity scale required an understanding and conceptual integration of parental behavior along the other three dimensions. Ainsworth and colleagues (1978) defined 
parental sensitivity as "noticing [an infant's signals], interpreting them accurately, and ... responding to them promptly and appropriately." (p. 40). Parents could be relatively insensitive in different ways suggested by the three relevant dimensions: for example, they might overtly or subtly reject their infant's bids for comfort, they might be relatively impervious to their infant's cues, or they might impose their own agenda instead of responding to cues in a way that would satisfy the infant (Ainsworth et al., 1974).

To date, most research has investigated associations between sensitivity and an array of developmental outcomes, whereas less attention has been directed to investigating the construct of sensitivity itself. However, the way in which sensitivity is conceptualized and assessed fundamentally influences research findings. Increased clarity regarding sensitivity and its measurement would clarify what it is exactly about parental behavior that gives rise to secure attachment. For example, historically, studies that have operationalized sensitivity as synchrony or mutuality, thus emphasizing the cooperative elements of maternal behavior, have yielded the strongest associations between parental sensitivity and attachment security (De Wolff \& Van IJzendoorn, 1997; Nievar \& Becker, 2008). Furthermore, some sensitivity-related parenting dimensions may prove more relevant than others not only to attachment formation, but to different spheres of subsequent child adaptation and development (Grusec \& Davidov, 2010). Precise identification of the dimensions of parenting most relevant to specific child outcomes could inform the development of well-targeted intervention efforts. Unfortunately, for the time being, "studies on the components of sensitivity are surprisingly rare" (Mesman \& Emmen, 2013, p. 495).

\section{The current study}


In the current study we used factor analysis to identify dimensions of maternal behavior related to Ainsworth's construct of sensitivity. We examined whether the latent structure of mothers' sensitivity-related behaviors would approximate the behavioral dimensions suggested by Ainsworth (1969; Ainsworth et al., 1978). As a measure of maternal sensitivity, the Maternal Behavior Q-Sort (MBQS; Pederson, Moran, \& Bento, 1999; 2009) provided a unique opportunity to conduct such an empirical analysis, because instead of summary rating scales, estimates of sensitivity are derived from ratings of 90 specific maternal behaviors, which were adapted from Ainsworth's original, in-depth descriptions of behavioral dimensions of parenting. This allowed the multidimensional structure to emerge from the data. Subsequently, we investigated the predictive validity of the empirically-derived dimensions by examining their associations with child attachment security, assessed during home visits, and attachment classifications, based on the Strange Situation procedure (Ainsworth et al., 1978).

\section{Method}

\section{Participants}

The initial sample consisted of 274 mother-infant dyads (135 boys, 139 girls) living in a large Canadian metropolitan area. Families were drawn randomly from birth lists of the Ministry of Health and Social Services. Criteria for participation were full-term pregnancy and the absence of known disability or severe delay in the infant. Mothers were between 19 and 45 years old $(M=30.9)$, had 15.6 years of education on average (from 8 to 23 years), and their average family income fell in the $\$ 60,000$ to $\$ 79,000$ bracket (from less than $\$ 20,000$ to over $\$ 100,000$ ). Most mothers (89\%) were European-Canadian.

\section{Procedure}


Data were collected through three home visits that lasted an average of 75 minutes when children were aged $12(M=12.6, S D=1.0 ; \mathrm{T} 1), 15(M=15.5, S D=0.8 ; \mathrm{T} 2)$, and 25 months $(M$ $=25.5, S D=1.5 ; \mathrm{T} 4)$, as well as during a laboratory assessment at 18 months $(M=18.3, S D=$ 1.0; T3). Data were collected from 274 mother-infant dyads at T1, 240 dyads at T2, 157 dyads at T3, and 173 dyads at T4. Families with incomplete data were not significantly different from those with complete data for all time points with regards to socio-demographic information and maternal sensitivity ratings (all $p \mathrm{~s}>.05$ ). Consequently, statistical power was maximized by running analyses separately for home- and lab-based assessments of attachment: analyses pertaining to security in the home were run on the 163 children for whom complete home observation data at $\mathrm{T} 1, \mathrm{~T} 2$, and $\mathrm{T} 4$ were available, whereas analyses pertaining to attachment classifications included the 157 children with valid T1 and T3 data.

As described by $* * *$ (omitted for blind review) who used part of this sample in their analyses, home visits were modeled after the work of Pederson and Moran (1995), and aimed at challenging the mother's capacity to divide her attention between competing demands, thus reproducing the natural conditions of daily life when caring for an infant. Restricting maternal availability to infant demands also is a classic trigger of the attachment system in infancy. The home-visit protocols were thus designed to create a challenging situation where maternal attention was being solicited by both the research tasks and the infant's demands. Visits included a brief interview with the mother, research tasks with the infant, a 10 to 20-minute free-play period, and a series of questionnaires that the mother was asked to complete while the infant was not kept busy by the research assistants.

Observations during these home visits were used to assess either maternal sensitivity or mother-child attachment security, as described below. To maximize the reliability of 
observations, research assistants attended a 2-day training workshop, during which they

reviewed videotapes of mother-infant interactions so as to practice coding maternal sensitivity or child attachment behavior. The assistants then performed their first few home visits with a more experienced colleague, and they completed the assessments together. When the junior home visitors were considered ready to rate maternal and child behavior, the first two or three visits were followed by a debriefing session with an experienced graduate student to review the salient elements of the visit before scoring maternal sensitivity or child attachment. The assistants then progressed to rating autonomously.

The Strange Situation Procedure was completed during the 18-month lab visit, as described below.

\section{Measures}

Maternal sensitivity. Maternal sensitivity was assessed at T1 (infant age: 12 months) using the Maternal Behavior Q-Sort (MBQS; Pederson \& Moran, 1995), a 90-item measure designed to assess the quality of maternal behaviors during in-home mother-infant interactions. A trained research assistant noted maternal behaviors throughout the visit and rated the MBQS immediately afterward, based on the entire observation period. Items describing potential maternal behaviors were sorted into nine piles, ranging from very unlike to very similar to the observed mother's behaviors. Based on this sort, each item was assigned a score varying between 1 and 9, indicating the extent to which it resembled the mother's behavior during the visit. The MBQS is significantly correlated with other measures of maternal behavior, such as the HOME Inventory and the Ainsworth scales (see Pederson \& Moran, 1995), and shows good temporal stability (Behrens, Parker, \& Kulkofsky, 2014; Tarabulsy et al., 2008). Its construct validity is demonstrated by meta-analytic data showing its predictive capacity with respect to child 
attachment security (Van IJzendoorn, Vereijken, Bakermans-Kranenburg, \& Riksen-Walraven, 2004).

Almost thirty percent $(29.8 \%)$ of the visits were conducted by two research assistants who completed the MBQS independently. Agreement between the two raters' sort was very $\operatorname{good}, I C C=.87$.

Attachment security in the home. At T2 (15 months) and T4 (2 years), mother-child attachment security was measured using the Attachment Behavior Q-Sort (AQS; Waters, 1995). The AQS is comprised of 90 items describing potential infant behaviors. The procedure is the same as with the MBQS, except that observations target infant rather than maternal behaviors. The sorting procedure allows two scores to be derived: infant attachment security and infant dependency on the caregiver. Both scores are obtained by correlating the observed sort with the standard criterion sorts provided by Waters (1995). Attachment security and dependency scores can thus vary from -1 (most insecure or independent) to 1 (prototypically secure or dependent). Inter-rater reliability was good, $I C C=.88$ at $\mathrm{T} 2$ and .72 at $\mathrm{T} 4$ (with $26.7 \%$ and $28.5 \%$ of doublecoded visits). Meta-analytic data suggest that the observer-completed AQS shows excellent construct validity, with attachment scores converging with maternal sensitivity, attachment security assessed with the Strange Situation Procedure (SSP), and child adaptation (Van IJzendoorn et al., 2004).

Lab-based attachment classifications. Children took part in the SSP (Ainsworth et al., 1978) with their mothers at T3 (18 months), in our laboratory. The SSP consisted of a series of eight brief ( 3 minutes) episodes, alternating moments of exploration in presence of the mother, separations (child is left alone or with a stranger), and reunions. The SSP allows for observation of children's behavior toward an attachment figure (the mother in this case) in a situation of 
moderate stress that increases throughout the procedure. Mother-child relationships were classified as secure, insecure-avoidant, insecure-resistant, or insecure-disorganized. Children in secure relationships responded to their mother's return by showing a desire for proximity and contact. They were effective in obtaining comfort from their mother when needed, and subsequently could resume exploration. Children in avoidant relationships ignored their mother or attempted few interactions with her upon reunion. Children in resistant relationships responded with persistent distress, often some anger, to their mother's attempt to interact with them upon reunion, and could not resume exploration. Finally, children in disorganized relationships exhibited odd, conflicted, or contradictory behaviors in the presence of their mother, thought to indicate a breakdown of their organized attachment strategy.

Videorecordings were scored by a coder certified as reliable by Sroufe and Carlson. Thirty-three percent were also independently rated by one of two other coders, also certified as reliable by Sroufe and Carlson. Inter-rater reliability was satisfactory, with coders agreeing on $83 \%$ of cases, $\kappa=.67$.

\section{Results}

\section{Descriptive statistics}

Of the 157 dyads who completed the SSP, 18 (11\%) were classified as avoidant, 118 $(75 \%)$ as secure, $10(6 \%)$ resistant, and $11(7 \%)$ disorganized. Regarding child behavior in the home, average security scores were $.39(S D=.28)$ at 15 months and $.44(S D=.29)$ at 2 years; dependency scores averaged -.04 $(S D=.22)$ and $-.10(S D=.22)$ at 15 months and 2 years.

\section{Latent structure of the MBQS}

The factor structure of the $90 \mathrm{MBQS}$ items was examined using an exploratory principal axis factor analysis with promax rotation. Parallel analysis (alpha $=.05$; O'Connor, 2000) was 
used to inform factor retention; thus, factors were retained if their explained variance exceeded that of a parallel factor derived from a random dataset. This analysis specified a 3-factor model accounting for 27 percent of the variance (17.1, 5.7, and 4.2 percent before rotation, respectively; sums of squared loadings following rotation were 12.6, 10.0, and 10.9). After rotation, 17 items loaded strongly $(>.5$ or $<-.5)$ on the first factor, 13 on the second, and 11 on the third factor. In second and third iterations of the factor analysis, items were removed if the primary factor loading was less than an absolute value of .5, and/or its cross-loading on another factor exceeded an absolute value of .2. The resultant 3-factor solution accounted for 48 percent of the variance, and after rotation included nine items loading on Factor 1, 11 on Factor 2, and seven on Factor 3. As displayed in Table 1, the majority of items loading on Factor 1 described mothers' ability to accurately perceive and interpret infants' cues, and to adjust the interaction correspondingly, so that infants appeared to find mothers' contributions enjoyable and supportive rather than becoming frustrated or overwhelmed. Accordingly, this factor was labeled “Cooperation/Attunement." Items loading on the second factor described mothers with positive mood and comments about their infant, who showed no signs of feeling overwhelmed, depressed or critical of the baby. The factor consequently was labeled "Positivity" as it mostly described maternal positive attitude toward the infant. Finally, items loading on the third factor described mothers' inconsistent attentiveness toward their infants, particularly when engaged in other tasks. Items were reverse-scored so that higher scores indicated more desirable parenting behavior for all dimensions, and the factor consequently was labeled "Accessibility/Availability:" mothers with high scores consistently were accessible and aware of their infant's cues.

Of the original 90 items, 27 were retained through factor analysis, each contributing to 
one of the three factors. Rather than using factor scores (which are sample-specific) for analyses, we created three scale scores by averaging items loading highly on each factor.. Internal consistency for these scales, together with descriptive statistics, inter-correlations and correlations with the global MBQS sensitivity score, are presented in Table 2.

\section{Relations between sensitivity and attachment}

To investigate the predictive validity of the three maternal behavior dimensions, correlations between the dimensions and infant attachment security, assessed with the AQS at 15 months and 2 years of age, were computed (Table 3 ). Discriminant validity was ascertained by correlating the maternal behavior dimensions with infants' dependency scores, also derived from the AQS. Drawing on the premise that sensitivity favors attachment security, namely a fluid balance between proximity-seeking and exploratory behavior in children (Ainsworth, 1985), central behavioral components of maternal sensitivity were expected to relate to infant security but not to dependency (which indicates a deficit in exploratory behavior). At both time points, attachment security was most strongly related to maternal Cooperation/Attunement, then Positivity, and then least with Accessibility/Availability (see Table 3). Associations involving Cooperation/Attunement were virtually identical in strength to parallel associations involving the global MBQS sensitivity score. In contrast, maternal behavior was not associated with infant dependency ratings, with one exception: maternal Accessibility/Availability (and the global MQBS score) was related to infant dependency at 15 months. Partial correlations with security, controlling for dependency scores, revealed similar associations, as did partial correlations with dependency, controlling for security scores.

Following up on these analyses, the three dimensions were entered together in two multiple regressions predicting attachment security. Predicting security at 15 months $(R=.38$, 
$F(3,159)=8.95, p<.001)$, maternal Cooperation/Attunement contributed uniquely, $\beta=.28, p=$ .001 . There was a similar trend for maternal Positivity $(\beta=.15, p=.059)$. Maternal Cooperation/Attunement also predicted security uniquely at 2 years $(\beta=.26, p=.003 ; R=.29$, $F(3,159)=4.74, p=.003)$.

Turning now to attachment assessed in the lab, a multivariate analysis of variance (MANOVA) was used to examine associations between Strange Situation classifications and the maternal behavior scales. Following up on the statistically significant omnibus test (Pillais' $F(9,459)=2.56, p=.007)$, attachment classifications were found to differ on Cooperation/Attunement $(F(3,153)=3.25, p=.024)$ and Accessibility/Availability $(F(3,153)=$ $3.30, p=.022)$, with a similar trend found also for Positivity $(F(3,153)=2.37, p=.073)$. Figure 1 shows average scores on each dimension by attachment classification. Post-hoc analyses using Tukey's HSD revealed that mothers in Avoidant attachment relationships were observed to be less Cooperative/Attuned $(p=.015)$ than mothers in Secure attachment relationships and less Accessible/Available than mothers in Resistant attachment relationships $(p=.032)$. Furthermore, mothers in Secure relationships showed more Positivity toward their infants than mothers in Disorganized attachment relationships. Other differences between attachment classifications did not achieve statistical significance.

A repeated-measures ANOVA with Greenhouse-Geisser correction was used to consider attachment-related differences in the patterning of these behavior dimensions. The repeatedmeasures variable was mothers' profile across the three behavior dimensions. There were two main effects: first, differences were observed in the average scores for each dimension, regardless of attachment classification $(F(2,152)=12.91, p<.001$; see Table 2 for descriptive statistics). Second, there was a between-subjects effect $(F(3,153)=3.50, p=.017)$, indicating 
attachment-related differences in the average score across the three dimensions. More importantly, these main effects were subsumed by an interaction involving attachment classification and the repeated-measures variable $(F(6,306)=2.80, p=.011)$, indicating attachment-related differences in the patterning, or profile, across the three maternal behavior dimensions. The interaction was probed further by dummy-coding three binary variables contrasting each insecure Strange Situation classification (i.e., Avoidant vs. not-Avoidant, etc.). These were entered simultaneously as between-subjects variables in custom-modeled repeatedmeasures ANOVAs ${ }^{1}$. The first analysis, contrasting dimensions 1 and 2 (Cooperation/Attunement vs. Positivity), revealed a distinct profile for Avoidant attachment, $F(1,153)=6.62, p=.011$. As seen in Figure 1, compared to other mothers, those in Avoidant attachment relationships displayed a distinct discrepancy between relatively low levels of Cooperation/Attunement and high levels of Positivity. In contrast, there was a statistical trend, $F(1,153)=3.15, p=.078$, for Disorganized attachment to be associated with the opposite pattern: high maternal Cooperation/Attunement and low Positivity. The second analysis, contrasting dimensions 1 and 3 (Cooperation/Attunement vs. Accessibility/Availability), revealed a difference unique to Disorganized attachment, $F(1,153)=3.91, p=.050$. Compared to other attachment classifications, Disorganized attachment was associated with a greater discrepancy between high Cooperation/Attunement and low Accessibility/Availability (Figure 1). Finally, contrasting dimensions 2 and 3 (Positivity and Accessibility/Availability) revealed another distinct profile for Avoidant attachment, $F(1,153)=4.33, p=.039$, with higher levels of Positivity compared to lower Accessibility/Availability. Mothers in Resistant attachment relationships were not distinguishable from others in their behavioral profile. 


\section{Discussion}

The current study's deconstruction of sensitivity provided an opportunity to examine associations involving mother-child attachment and distinct dimensions of sensitivity-related maternal behavior. In the current sample, a three-factor solution best described the patterning of discrete maternal behaviors. The first factor, Cooperation/Attunement, emphasized mothers' accurate interpretation of infants' cues, their capacity to adjust the interaction correspondingly, and their effectiveness in satisfying the infant. The second, Positivity, depicted mothers' positive attitude and delight in their infant. This factor primarily included mothers' praise vs. criticism of their children, and items reflecting positive vs. depressed mood. Finally, the third factor, Accessibility/Availability, focused on the consistency of mothers' psychological accessibility. Mothers with high scores on this third factor were aware of their infants even when occupied with other activities. These factors appear to correspond fairly closely to three of Ainsworth's four original maternal care scales: Cooperation/Attunement incorporated key elements of Ainsworth's Cooperation vs. Interference scale, Positivity was similar to Acceptance vs. Rejection, and Accessibility/Availability paralleled Ainsworth's Availability vs. Ignoring scale. In turn, elements of Cooperation/Attunement and Accessibility/Availability were featured in her Sensitivity vs. Insensitivity scale, comprised of multiple characteristics.

There were, however, some distinctions between Ainsworth's scales and the current factors. Maternal Positivity differed somewhat from Ainsworth's Acceptance vs. Rejection: Positivity items described mothers' overt feelings and communication, whereas Ainsworth additionally described more nuanced, subtle forms of rejection involving suppression of mothers' negative feelings. These more subtle forms would be more difficult to reliably observe and operationalize as discrete behaviors. The Positivity factor also included items referencing 
mothers' mood (overwhelmed/depressed, flat affect), whereas Ainsworth did not allude to depression in her scale. A second distinction concerns the range of behavior covered by the Availability/Accessibility dimension and Ainsworth's Availability vs. Ignoring scale. The low end of Ainsworth's scale depicts pronounced or sustained unresponsiveness, even to an infant's clear and prolonged cues, whereas items from the MBQS describing such unresponsiveness did not load on the third factor. Instead, the low end described mothers who were somewhat less psychologically available, particularly when preoccupied with other activities. As explained below, we attribute this difference to the low-risk nature of the current sample: a restricted range of maternal behavior, with less variability in the insensitive range, would limit applicability of items describing extreme insensitivity.

\section{Associations with attachment}

The three dimensions of maternal behavior were differentially associated with parentchild attachment security, as assessed in the home. Cooperation/Attunement was most strongly related to security, and uniquely predicted security when compared with the other maternal behavior dimensions. Maternal Positivity also was associated with security, although not as strongly. In contrast, Accessibility/Availability was minimally associated with security, and instead was associated with infant dependency. These differences correspond quite closely with prior meta-analytic findings (De Wolff \& Van IJzendoorn, 1997): whereas studies operationalizing sensitivity as Cooperation/Attunement yielded the strongest associations with attachment security, studies emphasizing maternal warmth (similar to Positivity) were less strongly related, and those focusing on degree of maternal involvement and supportive presence (closer to the current study's Accessibility/Availability) were minimally associated with security (Nievar \& Becker, 2008). These convergent findings speak to the importance of systematically 
delineating distinct aspects of parental caregiving behavior.

These results also suggest that Ainsworth's Cooperation vs. Interference dimension may be quite central to the concept of sensitivity and carry the bulk of its predictive power. This possibility is consistent with Ainsworth's emphasis on harmony within dyadic interactions (Ainsworth et al., 1971; Bretherton, 2013; Pederson, Bailey, Tarabulsy, Moran, \& Bento, 2014). In the current study, a 9-item Cooperation/Attunement factor was highly correlated $(r=.80)$ with the global 90-item MBQS score, and just as effective at predicting home-based security. Therefore, we suggest that the original Ainsworth's Cooperation vs. Interference scale may have been left aside too quickly by attachment researchers, and deserves renewed attention. Those using the Ainsworth scale of sensitivity should consider using the Cooperation scale as well, but also the Acceptance vs. Rejection and Accessibility vs. Ignoring scales. Studies based on these four scales would not only allow for replication (or lack thereof) of this study's findings suggesting the special importance of a Cooperation factor, but also would yield a multidimensional assessment of maternal behavior that could permit the use of composite (and thus stronger) indicators of parenting behavior, or the examination of behavioral profiles. Likewise, we suggest that MBQS users consider applying the current or other multi-dimensional approaches to the MBQS items. Alternatively, scholars needing a shorter instrument perhaps could rely on the herein identified nine items of the Cooperation/Attunement dimension, at least when aiming to predict child attachment security in the home.

However, when investigating the development of different types of insecure attachment as assessed by the SSP, the current results suggest that no single dimension is sufficient. Analyses revealed that different forms of insecurity were associated with different maternal behaviors. Avoidant attachment was related to lower levels of maternal Cooperation/Attunement 
than secure attachment, and to lower levels of Accessibility/Availability than resistant attachment (Figure 1). Furthermore, a more informative picture emerged when the three maternal dimensions were considered in conjunction: compared to the predominant secure strategy, different types of insecure attachment were associated with different patternings of maternal behavior profiles. Mothers in avoidant attachment relationships were relatively low on Cooperation/Attunement and Accessibility/Availability, but at the same time were observed to be fairly pleased with and positive toward their infants (high Positivity). This pattern was unique to avoidant attachment, and suggests that a positive relationship may have been observed at a superficial level, but a less harmonious relationship was revealed through attention to behaviors central to sensitivity. From an infant's perspective, positive interactions would be perceived quite differently if they were accompanied by interference instead of cooperation, or by psychological inaccessibility versus availability. This profile involving positivity together with indices of insensitivity bears some resemblance to Pederson and Moran's (1996) “Al-teaching” home classification, associated with avoidance in the SSP and characterized by mothers' instructive involvement during interactions, focus on the child's cognitive development, and some intrusiveness.

In contrast, disorganized attachment was distinguished from secure attachment by lower levels of Positivity. A distinct profile also was observed for mothers of infants classified as disorganized: they were highly Cooperative/Attuned but at the same time were somewhat less Positive toward, and especially less Accessible/Available to, their infants. This incongruence, with mothers supporting their infants in some ways but not in others, may have presented infants with conflicting representations of the relationship. The possibility that infants' disorganized behavior may be due to receiving such mixed messages from their caregivers is consistent with 
theoretical accounts of the origins of disorganized attachment (Hesse \& Main, 2000; LyonsRuth, Bronfman, \& Atwood, 1999), in that infants are thought to grapple with multiple working models of their relationship with the caregiver, and to have difficulty assimilating such contradictory information.

It is notable that mothers in resistant attachment relationships were not distinguished by significantly lower levels of any maternal dimension; they were only, in fact, higher on Accessibility/Availability than mothers of avoidant infants (Figure 1). These results contrast with the prevailing consensus that mothers in resistant attachment relationships are inconsistently available and responsive (and thus less sensitive) to their infants' cues (Ainsworth et al., 1978; Cassidy \& Berlin, 1994); however, evidence for this widely-held premise is somewhat equivocal. Although historically, a number of research groups have found that mothers in resistant attachment relationships were less involved with, or responsive to, their infants (see Cassidy \& Berlin, 1994), in the NICHD ECCRN study (1997) mothers of secure and resistant infants showed virtually indistinguishable levels of sensitivity. More recently, others also have failed to replicate an association between resistant attachment and maternal insensitivity (Pederson et al., 2014). We suggest that, consistent with the principle of equifinality, it may be that there is more than one way to develop a resistant attachment relationship. Whereas some such relationships may be characterized by maternal insensitivity, or inconsistent availability, others may involve excessive relational closeness (suggested by Accessibility/Availability levels in Figure 1). A high degree of availability and monitoring, especially in a safe and familiar context like the home, may be excessive, and could perhaps indicate difficulty supporting the infant's autonomy and exploration, an important component of secure attachment (Bernier, Matte-Gagné, Bélanger, \& Whipple, 2014). In fact, Figure 1 suggests that mothers of secure infants were characterized by 
moderate levels of Accessibility/Availability. Finally, returning to the possibility that maternal inconsistency gives rise to resistant attachment relationships, repeated observations may be necessary to capture the range of behaviors involved in such an inconsistent caregiving style (Pederson et al., 2014).

\section{Limitations}

The current study took an empirical approach to delineating dimensions of maternal behavior related to sensitivity. Strengths of this approach included the use of numerous specific behavioral descriptors, and parallel analysis to inform factor retention. However, the current analysis was limited in a number of ways. First, sensitivity was rated at one time point only. Future studies should consider the use of repeated assessments, which will allow researchers to address not only the stability of different aspects of maternal behavior, but also the invariance of the factor structure that was identified here at 12 months. Second, the analysis was restricted to item content based on Ainsworth's original conceptualization, and as described by the creators of the MBQS. Sensitivity has been conceptualized and operationalized in other ways that were not represented by behavioral items in the current study, for instance emotional availability (Biringen, 2008) or synchrony (Feldman, 2007).

Third, much of the variance among MBQS items was not accounted for by the threefactor solution. Of the 90 items, approximately half loaded highly on one of the three factors in the first iteration, and approximately one third were retained in the final solution. There are a number of probable reasons for this. Unlike other measures typically subjected to factor analysis, MBQS items were designed to capture a broad array of maternal behaviors, and a substantial number of these items were not considered particularly reflective of parental sensitivity. The purpose of these items was to provide a broader perspective on a mother's approach to 
interaction, within which to situate an assessment of sensitivity, so as to avoid halo effects (Moran, Pederson, \& Tarabulsy, 2011; Pederson \& Moran, 1995). Many such items did not load strongly on any of the factors, for instance "Uses sibling or television to keep B entertained," "Instructive during interactions with B," or "Provides nutritional snacks." Furthermore, although other items appear conceptually related to sensitivity, q-sort items traditionally have been sorted into a forced distribution, and therefore coders must make decisions not only about how well an item describes a parent's behavior, but how important it is to prioritize the item's placement into the "most descriptive" category, thus giving it a greater weighting in the final score. For example, although "Displays affection by touching, caressing" and "Interventions satisfy B" both are considered positive and related to sensitivity, creators of the MBQS judged the latter item to be more reflective of sensitivity; therefore, if both items equally describe a parent's interactions, due to forced sorting constraints the former item would receive a lesser weighting. Items given less extreme weights, and items that tend to be sorted in the middle piles because they are considered less relevant to sensitivity, will have lower variability across a sample and thus are less likely to emerge in a factor analysis. That said, the Positivity factor emerging from the current analysis was comprised primarily of items considered relatively less central to the sensitivity construct by creators of the MBQS, thus demonstrating that such factors can emerge. Inclusion of such a large number of items also resulted in a fairly low ratio of participants to items. Although we considered addressing this limitation by selecting only the most theoretically relevant items for factor analysis, ultimately we opted to impose no such a priori restrictions on the data, consistent with our goal of empirically deriving, rather than theoretically prescribing, the factor structure. Considering the heterogeneous initial pool of items and the exploratory empirical approach chosen, it is striking that the resultant conceptually distinct 
factors corresponded closely to Ainsworth's scales, and that their patterning was meaningfully associated with different insecure attachment patterns.

The current factors are necessarily sample-specific: future research with different populations may identify somewhat different parenting behaviors and factor structures. Behavior dimensions may be more strongly interrelated in low-risk samples such as this one, characterized by high average sensitivity. Ainsworth et al. (1971) noted that "mothers who are sensitive to their babies' signals tend to be also accessible, cooperative, and accepting” (p. 45). In contrast, research with samples at higher risk for insensitive parenting may yield behavior dimensions that are less interrelated if parents' insensitivity is expressed in different ways (Bailey, Waters, Pederson \& Moran, 1999). In fact, Bailey et al. (1999; 2007) identified a different q-factor structure in two different at-risk samples: sensitive (vs. insensitive), emotionally detached, and interfering. These analyses grouped mothers rather than items; however, assuming that a similar factor structure would have emerged in a traditional factor analysis of items, the differences between the q-factor structure they identified and the factors revealed in the current study are exactly the sort of differences one would expect when comparing low- and high-risk samples. A high-risk sample would capture more variance at the low end of the sensitivity spectrum, and resultant factors would involve more extreme forms of insensitivity (i.e., emotionally neglectful behavior rather than intermittent inaccessibility) whereas a low-risk sample would include greater variance within the sensitive range, resulting in the more subtle distinctions observed in the current study.

In line with the high mean levels of sensitivity observed here, a large proportion of dyads were classified as secure. Although other studies have reported comparable levels of security in low-risk community samples (e.g., Behrens, Parker, \& Haltigan, 2011; McElwain \& Booth- 
LaForce, 2006; Waters et al., 2000), the small proportions of insecure infants clearly suggests that the current findings require replication. At the same time, however, the sample size for this study was large by attachment research standards, and thus yielded numbers of infants in each insecure category (18 avoidant, 10 resistant, and 11 disorganized infants) comparable to those observed in most published attachment studies. The fact remains, however, that this sample is skewed toward security, and that further research is necessary to examine the applicability of the current results to at-risk samples.

\section{Future directions}

Continued exploration of the core behavioral dimensions of sensitivity, and of classification-specific distinctions in the patterning of these dimensions, is needed to continue to elaborate our understanding of how attachment relationships develop. Although, as mentioned above, researchers looking for a relatively brief measure of sensitivity might consider the use of the nine items of the Cooperation/Attunement dimension identified here, we think that true understanding of the formation of attachment relationships is more likely to be achieved with a multi-dimensional approach to the assessment of parenting behavior. One global score of "sensitivity" does not yield the information inherent in a parent's profile across different behavioral dimensions, and it is unlikely that a rich, complex phenomenon as the quality of a parent-child relationship can be explained in a simple manner.

It is our hope that future research focus not only on distinct aspects of parental behavior that predict infant attachment, but also on how these distinct behavioral dimensions relate to children's developmental outcomes more broadly, beyond attachment security and insecurity. In addition, the most crucial aspects of parenting may vary not only according to spheres of child functioning, but also across children. While there no longer is any doubt as to the crucial 
importance of parenting for child development, the time seems ripe to become more precise regarding what aspects or combinations of aspects of parenting benefit (or hinder) which aspects of functioning, and for which specific children. Only a multi-dimensional approach to the assessment of parenting, such as that allowed by the deconstruction of maternal sensitivity, will allow us to answer these complex but essential questions. 


\section{References}

Ainsworth, M. D. S. (1969). Maternal sensitivity scales. Retrieved from Attachment Theory \& Research@ Stonybrookwebsite:

http://www.psychology.sunysb.edu/attachment/measures/content/ainsworth_scales.html

Ainsworth, M.D.S. (1985). Attachments across the life span. Bulletin of the New York Academy of Medicine, 61, 792-812.

Ainsworth, M.D.S. \& Bell, S.M. (1970). Attachment, exploration, and separation: Illustrated by the behavior of one-year-olds in a Strange Situation. Child Development, 41, 49-67. doi: $10.2307 / 1127388$

Ainsworth, M.D.S., Bell, S.M., \& Stayton, D.J. (1971). Individual differences in Strange Situation behavior in one year olds. In H.R. Schaffer (Ed.), The origins of human social relations. New York: Academic Press.

Ainsworth, M. D. S., Bell, S. M., \& Stayton, D. J. (1974). Infant-mother attachment and social development: 'Socialisation' as a product of reciprocal responsiveness to signals. In M. Richards (Ed.), The integration of a child into a social world (pp. 99-136). London: Cambridge University Press.

Ainsworth, M.D.S., Blehar, M.C., Waters, E., \& Wall, S. (1978). Patterns of attachment: A psychological study of the Strange Situation. Hillsdale, NJ: Erlbaum.

Atkinson, L., Paglia, A., Coolbear, J., Niccols, A., Parker, K.C.H., \& Guger, S. (2000). Attachment security: A meta-analysis of maternal mental health correlates. Clinical Psychology Review, 20, 1019-1040. doi: 10.1016/S0272-7358(99)00023-9 
Bailey, H.N., Moran, G., Pederson, D.R., \& Bento, S. (2007). Understanding the transmission of attachment using variable- and relationship-centered approaches. Development and Psychopathology, 19, 313-343. doi:10.1017/S0954579407070162

Bailey, H.N., Waters, C.A., Pederson, D.R., \& Moran, G. (1999). Ainsworth revisited: An empirical analysis of interactive behavior in the home. Attachment and Human Development, 1, 191-216. doi: 10.1080/14616739900134231

Bakermans-Kranenburg, M.J., Van IJzendoorn, M.H., \& Juffer, F. (2003). Less is more: Metaanalyses of sensitivity and attachment interventions in early childhood. Psychological Bulletin, 129, 195-215. doi: 10.1037/0033-2909.129.2.195

Beckwith, L., Cohen, S.E., \& Hamilton, C.E. (1999). Maternal sensitivity during infancy and subsequent life events relate to attachment representation at early adulthood. Developmental Psychology, 35, 693-700. doi: 10.1037/0012-1649.35.3.693

Behrens, K.Y., Parker, A.C., \& Haltigan, J.D. (2011). Maternal sensitivity assessed during the Strange Situation Procedure predicts child's attachment quality and reunion behaviors. Infant Behavior and Development, 34, 378-381. doi: 10.1016/ j.infbeh.2011.02.007

Behrens, K.Y., Parker, A.C., \& Kulkofsky, S. (2014). Stability of maternal sensitivity across time and contexts with q-sort measures. Infant and Child Development, 23, 532-541. doi: 10.1002/icd.1835

Bernier, A., Matte-Gagné, C., Bélanger, M-È., \& Whipple, N. (2014). Taking stock of two decades of attachment transmission gap: Broadening the assessment of maternal behavior. Child Development, 85, 1852-1865. doi: 10.1111/cdev.12236

Biringen, Z. (2008). The Emotional Availability (EA) Scales (4th edition). Unpublished manual, Colorado State University, Boulder, CO. 
Cassidy, J., \& Berlin, L.J. (1994). The insecure/ambivalent pattern of attachment: Theory and research. Child Development, 65, 971-991. doi: 10.1111/j.1467-8624.1994.tb00796.x

De Wolff, M.S., \& Van IJzendoorn, M.H. (1997). Sensitivity and attachment: A meta-analysis on parental antecedents of infant attachment. Child Development, 68, 571-591. doi: 10.1111/j.1467-8624.1997.tb04218.x

Fearon, R.P., Bakermans-Kranenburg, M.J., Van IJzendoorn, M.H., Lapsley, A.M., \& Roisman, G.I. (2010). The significance of insecure attachment and disorganization in the development of children's externalizing behavior: A meta-analytic study. Child Development, 81, 435-456. doi: 10.1111/j.1467-8624.2009.01405.x

Feldman, R. (2007). Parent-infant synchrony: Biological foundations and developmental outcomes. Current Directions in Psychological Science, 16, 340-345. doi: 10.1111/j.1467-8721.2007.00532.x

Fraley, R.C., Roisman, G.I., \& Haltigan, J.D. (2013). The legacy of early experiences in development: Formalizing alternative models of how early experiences are carried forward over time. Developmental Psychology, 49, 109-126. doi: 10.1037/a0027852

Goldsmith, H.H. \& Alansky, J.A. (1987). Maternal and infant temperamental predictors of attachment: A meta-analytic review. Journal of Consulting and Clinical Psychology, 55, 805-816. doi: 10.1037/0022-006X.55.6.805

Groh, A.M., Roisman, G.I., Van IJzendoorn, M.H., Bakermans-Kranenburg, M.J., \& Fearon, R. P. (2012). The significance of insecure and disorganized attachment for children's internalizing symptoms: A meta-analytic study. Child Development, 83, 591-610. doi: 10.1111/j.1467-8624.2011.01711.x

Grusec, J.E., \& Davidov, M. (2010). Integrating different perspectives on socialization theory 
and research: A domain-specific approach. Child Development, 81, 687-709. doi : 10.1111/j.1467-8624.2010.01426.x

Guttentag, C.L., Landry, S.H., Williams, J.M., Baggett, K.M., Noria, C.W., Borkowski, J.G., . . Ramey, S.L. (2014). “My Baby \& Me”: Effects of an early, comprehensive parenting intervention on at-risk mothers and their children. Developmental Psychology, 50, 14821496. doi: 10.1037/a0035682

Hesse, E. \& Main, M. (2000). Disorganized infant, child, and adult attachment: Collapse in behavioral and attentional strategies. Journal of the American Psychoanalytic Association, 48, 1097-1127. doi: 10.1177/00030651000480041101

Kochanska, G., Kim, S., Boldt, L.J., \& Nordling, J. (2013). Promoting toddlers' positive socialemotional outcomes in low-income families: A play-based experimental study. Journal of Clinical Child and Adolescent Psychology, 42, 700-712. doi: 10.1080/15374416.2013. 782815

Leerkes, E.M., Blankson, A.N., \& O'Brien, M. (2009). Differential effects of maternal sensitivity to infant distress and non-distress on social-emotional functioning. Child Development, 80, 762-775. doi: 10.1111/j.1467-8624.2009.01296.x

Lyons-Ruth, K., Bronfman, E., \& Atwood, G. (1999). A relational diathesis model of hostilehelpless states of mind: Expressions in mother-infant interaction. In J. Solomon \& C. George (Eds.), Attachment Disorganization (pp. 33-70). New York: Guilford Press.

McElwain, N.L. \& Booth-LaForce, C. (2006). Maternal sensitivity to infant distress and nondistress as predictors of infant-mother attachment security. Journal of Family Psychology, 20, 247-255. doi: 10.1037/0893-3200.20.2.247 
Mesman, J., \& Emmen, R.A.G. (2013). Mary Ainsworth's legacy: A systematic review of observational instruments measuring parental sensitivity. Attachment and Human Development, 15, 485-506. doi: 10.1080/14616734.2013.820900

Moran, G., Pederson, D.R., \& Tarabulsy, G. M. (2011). Becoming sensitive to sensitivity: Lessons learned from the development of the Maternal Behavior Q-Sort. In D.W. Davis \& M. C. Logsdon (Eds.), Maternal Sensitivity: A Scientific Foundation for Practice (pp. 259-281). Hauppauge, NY: Nova Science Publishers.

NICHD Early Child Care Research Network. (1997). The effects of infant child care on infantmother attachment security: Results of the NICHD study of early child care. Child Development, 68, 860-879. doi: 10.2307/1132038

NICHD Early Child Care Research Network. (1998). Early child care and self-control, compliance, and problem behavior at twenty-four and thirty-six months. Child Development, 69, 1145-1170. doi: 10.2307/1132367

NICHD Early Child Care Research Network. (2005). Early child care and children's development in the primary grades: Follow-up results from the NICHD Study of Early Child Care. American Educational Research Journal, 42, 537-570. doi: http://dx.doi.org/10.3102/00028312042003537

Nievar, M.A. \& Becker, B.J. (2008). Sensitivity as a privileged predictor of attachment: A second perspective on De Wolff and van IJzendoorn's meta-analysis. Social Development, 17, 102-114. doi: 10.1111/j.1467-9507.2007.00417.x

O’Connor, B.P. (2000). SPSS and SAS programs for determining the number of components using parallel analysis and Velicer's MAP test. Behavior Research Methods, Instruments, and Computers, 32, 396-402. doi: 10.3758/BF03200807 
Pederson, D.R., Bailey, H.N., Tarabulsy, G.M., Bento, S., \& Moran, G. (2014). Understanding sensitivity: Lessons learned from the legacy of Mary Ainsworth. Attachment and Human Development, 16, 261-270. doi: 10.1080/14616734.2014.900094

Pederson, D.R., \& Moran, G. (1995). A categorical description of infant-mother relationships in the home and its relation to Q-sort measures of infant-mother interaction. In E. Waters et al. (Eds.), New Growing Points of Attachment Theory and Research. Monographs of the Society for Research in Child Development, 60 (Serial no. 244, pp.111-132).

Pederson, D. R., Moran, G., \& Bento, S. (1999). Maternal Behaviour Q-sort. Retrieved from The Selected Works of Greg Moran’s Web site: http://works.bepress.com/gregmoran/1.

Pederson, D. R., Moran, G., \& Bento, S. (2009). Assessing Maternal Sensitivity and the Quality of Mother-Infant Interaction. Manual available upon request from the authors at mailto:gmoran2@uwo.ca.

Raby, K.L., Roisman, G.I., Fraley, R.C., \& Simpson, J.A. (2015). The enduring predictive significance of early maternal sensitivity: Social and academic competence through age 32 years. Child Development, 86, 695-708. doi: 10.1111/cdev.12325

Smith, K. E., Landry, S. H., \& Swank, P. R. (2006). The role of early maternal responsiveness in supporting school-aged cognitive development for children who vary in birth status. Pediatrics, 117, 1608-1617. doi: 10.1542/peds.2005-1284

Sroufe, L.A., Egeland, B., Carlson, E., \& Collins, W.A. (2005). The development of the person: The Minnesota study of risk and adaptation from birth to adulthood. New York: Guilford Press. 
Tarabulsy, G.M., Provost, M.A., Larose, S., Moss, E., Lemelin, J-P., Moran, G., . . Pederson, D. R. (2008). Similarities and differences in mothers' and observers' ratings of infant security on the Attachment Q-Sort. Infant Behavior and Development, 31, 10-22. doi: http://dx.doi.org/10.1016/j.infbeh.2007.05.002

Van IJzendoorn, M.H., Vereijken, C.M.J.L., Bakermans-Kranenburg, M.J., \& Riksen-Walraven, J.M. (2004). Assessing attachment security with the Attachment Q-Sort: Meta-analytic evidence for the validity of the observer AQS. Child Development, 75, 1188-1213. doi: 10.1111/j.1467-8624.2004.00733.x

Waters, E. (1995). Appendix A: The Attachment Q-SET (Version 3.0). Monographs of the Society for Research in Child Development, 60, 234-246. doi: 10.2307/1166181

Waters, E., Merrick, S., Treboux, D., Crowell, J., \& Albersheim, L. (2000). Attachment security in infancy and early adulthood: A twenty-year longitudinal study. Child Development, 71, 684-689. doi: 10.2307/1132386 


\section{${ }^{1}$ Footnote}

${ }^{1}$ The secure vs. insecure distinction was not included in this follow-up analysis because including all four dichotomized variables created statistical redundancy. A separate follow-up analysis contrasting secure and insecure patterns revealed no significant differences. Thus, maternal behavior dimensions differed according to type of insecurity, rather than insecurity per se. Similarly, home-based security scores using the AQS were not associated with Strange Situation-assessed attachment security. 
Table 1

Factor Loadings from the Pattern Matrix

\begin{tabular}{|c|c|}
\hline $\begin{array}{l}\text { Factor } \\
\text { Loadings }\end{array}$ & Item Descriptions \\
\hline \multicolumn{2}{|c|}{ Factor 1: Cooperation/Attunement } \\
\hline .85 & 54 (34) Interactions revolve around baby's tempo and current state. \\
\hline-.79 & $\begin{array}{l}74 \text { (16) Often misses "slow down" or "back off" signals from baby during } \\
\text { face-to-face play. }\end{array}$ \\
\hline-.75 & $\begin{array}{l}57 \text { (opposite of 68). Subjects baby to constant and unphased barrage of } \\
\text { stimulation; baby overwhelmed. }\end{array}$ \\
\hline .75 & $\begin{array}{l}29 \text { (53) Slows pace down; waits for baby's response in face-to-face } \\
\text { interactions. }\end{array}$ \\
\hline-.70 & $\begin{array}{l}73 \text { (17) Content and pace of interactions with the baby seem to be set by } \\
\text { mother rather than according to baby's responses. }\end{array}$ \\
\hline .67 & $\begin{array}{l}53 \text { (35) Well-resolved interaction with baby - interaction ends when baby is } \\
\text { satisfied. }\end{array}$ \\
\hline-.62 & 59. (similar to 7) Rough or intrusive in interactions with baby. \\
\hline .60 & 12 (62) Interprets cues correctly as evidenced by baby’s response. \\
\hline .51 & $\begin{array}{l}60 \text { (29) When baby is distressed, is able to quickly and accurately identify } \\
\text { the source. }\end{array}$ \\
\hline \multicolumn{2}{|c|}{ Factor 2: Positivity } \\
\hline .70 & 37. Comments are generally positive when speaking about baby \\
\hline
\end{tabular}




\begin{tabular}{|c|c|}
\hline .67 & 42 (43) Is animated in social interactions with baby. \\
\hline-.67 & 26 (similar to 60) Critical in her descriptions of baby. \\
\hline .66 & 36. Predominantly positive mood about baby. \\
\hline-.64 & 41. Flat affect when interacting with baby. \\
\hline .64 & 40 (45) Praise directed toward baby. \\
\hline .62 & 21 (similar to 57) Is delighted over baby. \\
\hline .56 & 38. (opposite of 10) Seldom speaks to the baby directly. \\
\hline-.56 & 69. (similar to 21) Seems overwhelmed, depressed. \\
\hline-.53 & 27. Seems "long suffering" in her attitude about her maternal duties. \\
\hline .51 & $\begin{array}{l}\text { 39. (similar to 46) When holding, cuddles baby as a typical mode of } \\
\text { interaction; molds baby to self. }\end{array}$ \\
\hline \multicolumn{2}{|c|}{ Factor 3: Accessibility/Availability } \\
\hline .90 & $\begin{array}{l}88 \text { (similar to 4) Often seems to forget baby is present in the room during } \\
\text { interaction with visitor. }\end{array}$ \\
\hline .87 & 62 (similar to 22) Preoccupied with interview - seems to ignore baby. \\
\hline-.84 & $\begin{array}{l}63 \text { (27) Monitors and responds to baby even when engaged in some other } \\
\text { activity such as cooking or having a conversation with visitor. }\end{array}$ \\
\hline .84 & $\begin{array}{l}65 \text { (25) Not skillful in dividing her attention between baby and competing } \\
\text { demands; thus misses baby's cues. }\end{array}$ \\
\hline-.62 & 61 (similar to 2) Seems to be aware of baby even when not in the same room. \\
\hline .62 & $\begin{array}{l}76 \text { (similar to 14) Sometimes will break off from the child in mid-interaction } \\
\text { to speak to visitor or attend to some other activity that suddenly comes to } \\
\text { mind. }\end{array}$ \\
\hline
\end{tabular}




\begin{tabular}{|l|l|}
\hline-.60 & $67(23)$ When in the same room as baby, provides baby with unrestricted \\
& access to her. \\
\hline
\end{tabular}

Note. $N=274$. Items are listed if they loaded $>.5($ or $<-.5)$ on a factor, and no cross-loadings $>$.2. Items not listed did not load strongly on any of the factors. Numbers pertain to the $2^{\text {nd }}$ version of the MBQS, which was used in the current study; numbers in parentheses correspond to parallel or similar items in the $3^{\text {rd }}$ version of the MBQS. Other new items in the $3^{\text {rd }}$ version that bear conceptual similarity to Factor 1 items are as follows: 7(R), 17(R), 30(R), 32(R), 35, $44,62,89$. 
Table 2

Descriptive statistics, internal consistency, and inter-correlations for maternal behavior scales

\begin{tabular}{|c|c|c|c|c|c|c|}
\hline & Mean (SD) & Alpha & Correlation & \multicolumn{3}{|c|}{ Inter-correlations } \\
\hline & & & & (1) & (2) & (3) \\
\hline $\begin{array}{l}\text { (1) Cooperation/Attunement } \\
\text { (9 items) }\end{array}$ & $7.24(1.40)$ & .90 & .80 & 1.00 & & \\
\hline (2) Positivity (11 items) & $7.50(1.24)$ & .89 & .51 & .24 & 1.00 & \\
\hline $\begin{array}{l}\text { (3) Accessibility/Availability } \\
\text { (7 items) }\end{array}$ & $6.56(1.66)$ & .90 & .71 & .43 & .21 & 1.00 \\
\hline
\end{tabular}

Note. $N=274 ;$ 's for correlations $<.001$. MBQS, MBQS overall sensitivity score. 
Table 3

Associations between maternal behavior dimensions and attachment security and dependency in the home

\begin{tabular}{|c|c|c|c|c|}
\hline & \multicolumn{3}{|c|}{ Dimensions identified through factor analysis } & \multirow{2}{*}{$\begin{array}{c}\text { MBQS } \\
\text { Sensitivity }\end{array}$} \\
\hline & $\begin{array}{l}\text { Cooperation/ } \\
\text { Attunement }\end{array}$ & Positivity & $\begin{array}{l}\text { Accessibility/ } \\
\text { Availability }\end{array}$ & \\
\hline $\begin{array}{l}\text { Security } \\
15 \text { months }\end{array}$ & $\begin{array}{c}.35^{* *} \\
\left(.33^{* *}\right)\end{array}$ & $\begin{array}{c}.25 * * \\
(.22 * *)\end{array}$ & $\begin{array}{l}.20^{*} \\
(.16)\end{array}$ & $\begin{array}{c}.35 * * \\
(.31 * *)\end{array}$ \\
\hline $\begin{array}{l}\text { Security } \\
2 \text { years }\end{array}$ & $\begin{array}{l}.26 * * \\
(.27 * *)\end{array}$ & $\begin{array}{c}.17 * \\
\left(.18^{*}\right)\end{array}$ & $\begin{array}{c}.06 \\
(.05)\end{array}$ & $\begin{array}{l}.24 * * \\
(.24 * *)\end{array}$ \\
\hline $\begin{array}{l}\text { Dependency } \\
15 \text { months }\end{array}$ & $\begin{array}{c}.11 \\
(-.02)\end{array}$ & $\begin{array}{c}.13 \\
(.05)\end{array}$ & $\begin{array}{l}.16^{*} \\
(.09)\end{array}$ & $\begin{array}{l}.16^{*} \\
(.04)\end{array}$ \\
\hline $\begin{array}{l}\text { Dependency } \\
2 \text { years }\end{array}$ & $\begin{array}{c}.01 \\
(-.05)\end{array}$ & $\begin{array}{l}-.05 \\
(-.09)\end{array}$ & $\begin{array}{c}.07 \\
(.06)\end{array}$ & $\begin{array}{c}.02 \\
(-.04)\end{array}$ \\
\hline
\end{tabular}

Note. $N=163$ with complete home observation data at T1, T2, and T4.

Partial correlations, in parentheses, control for the other variable (security or dependency) assessed at the same time point.

$* p<.05 . * * p<.01$. 


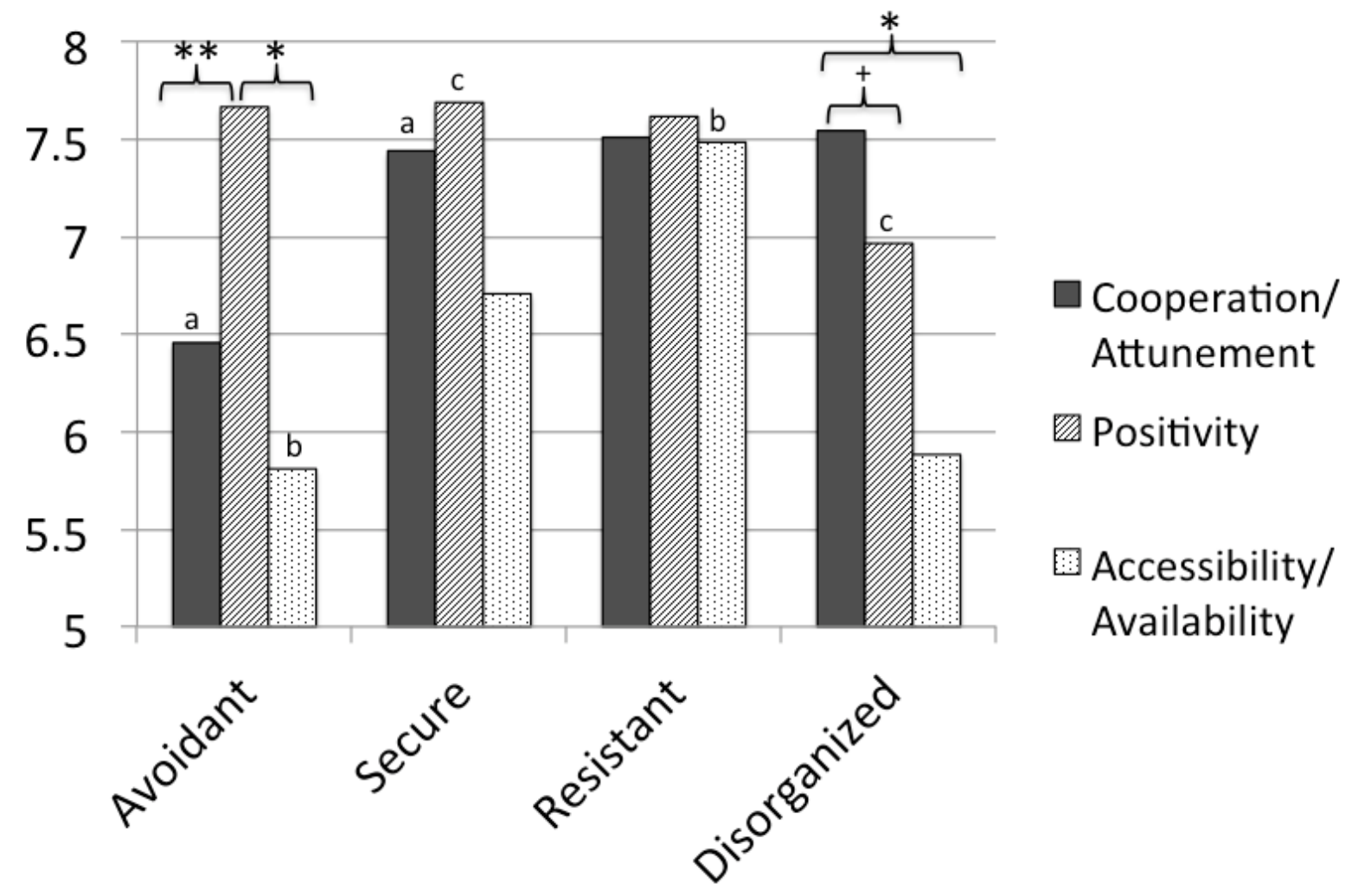

Figure 1. Mean scores on maternal dimensions by attachment classification

Note. The same letters (e.g., a vs. a) indicate means that differed statistically significantly in post-hoc analyses following the MANOVA. Brackets indicate profile discrepancies unique to an attachment classification, as indicated by repeated measures analyses. ${ }^{* *} p<.01,{ }^{*} p<.05,{ }^{+} p<$ .10 . 